\title{
Cognitive performance and its relationship with postprandial metabolic changes after ingestion of different macronutrients in the morning
}

\author{
Karina Fischer ${ }^{1}{ }^{*}$, Paolo C. Colombani ${ }^{1}$, Wolfgang Langhans ${ }^{2}$ and Caspar Wenk ${ }^{1}$ \\ ${ }^{1}$ INW Nutrition Biology and ${ }^{2} I N W$ Physiology, Department of Agriculture and Food Science, Swiss Federal Institute of \\ Technology Zurich, CH-8092 Zurich, Switzerland
}

(Received 25 February 2000 - Revised 8 August 2000 - Accepted 22 September 2000)

\begin{abstract}
The effect of carbohydrate, protein and fat ingestion on simple as well as complex cognitive functions and the relationship between the respective postprandial metabolic changes and changes in cognitive performance were studied in fifteen healthy male students. Subjects were tested in three sessions, separated by 1 week, for short-term changes in blood variables, indirect calorimetry, subjective performance and different objective performance tasks using a repeatedmeasures counterbalanced cross-over design. Measurements were made after an overnight fast before and hourly during $3 \mathrm{~h}$ after test meal ingestion. Test meals consisted of either pure carbohydrates, protein or fat and were served as isoenergetic $(1670 \mathrm{~kJ})$ spoonable creams with similar sensory properties. Most aspects of subjective performance did not differ between test meals. For all objective tasks, however, postprandial cognitive performance was best after fat ingestion concomitant with an almost constant glucose metabolism and constant metabolic activation state measured by glucagon:insulin (G:I). In contrast, carbohydrate as well as protein ingestion resulted in lower overall cognitive performance, both together with partly marked changes $(P<0.001)$ in glucose metabolism and metabolic activation. They also differently affected specific cognitive functions $(P<0.05)$ in relation to their specific effect on metabolism. Carbohydrate ingestion resulted in relatively better short-term memory and accuracy of tasks concomitant with low metabolic activation, whereas protein ingestion resulted in better attention and efficiency of tasks concomitant with higher metabolic activation. Our findings support the concept that good and stable cognitive performance is related to a balanced glucose metabolism and metabolic activation state.
\end{abstract}

Cognitive performance: Macronutrient ingestion: Postprandial metabolism

The relationship between postprandial metabolism and cognitive behaviour after macronutrient ingestion is only marginally characterised, and outcomes are not conclusive. Furthermore, there is little understanding of how the multitude of postprandial metabolic changes affect simple and complex cognitive functions as well as different mood states (for review, see Bellisle et al. 1998).

The inconsistent results regarding macronutrient ingestion and cognitive behaviour can mainly be explained by methodological differences, such as consideration of baseline values or differences in time intervals of postprandial measurements, as well as by the difficulty in defining and differentiating indices to study. In most studies mixed meals high in one macronutrient were tested instead of pure macronutrient preparations, and interactions between macronutrients were not considered. Observed effects can not therefore be related unambiguously to a single macronutrient. Furthermore, the complex meals usually differed in energy content, volume and sensory properties (e.g. taste, pleasantness, texture), which may all influence behaviour and mental performance (Craig, 1986; Rogers, 1995). Although recent techniques allow measurement of single aspects of cerebral nerve cell metabolism, such as neurotransmitter activity or glucose metabolism, it is reasonable to investigate peripheral metabolic changes (Cahill \& McGaugh, 1996) in order to study the complex mechanisms and interactions by which macronutrient ingestion modifies cognitive functions. Generally, three targets must be considered that directly or indirectly influence acute cognitive functioning after macronutrient ingestion: energy supply to nerve cells (Owen et al. 1967; Gold, 1995), neurotransmitter and hormone modulations

Abbreviations: BHB, $\beta$-hydroxybutyrate; choice RT, choice visual and auditory reaction time; EE, energy expenditure; EMG, electromyography;

G:I, glucagon:insulin; POMS, profile of mood states; simple RT, simple visual reaction time.

* Corresponding author: Karina Fischer, fax +41 1632 1128, email karina.fischer@inw.agrl.ethz.ch 
(Fernstrom, 1977; Gold \& Stone, 1988; Cahill \& McGaugh, 1996) and activation or deactivation of the nervous system (Nielson \& Jensen, 1994). However, only individual target factors have been determined with regard to cognitive performance (Pollitt et al. 1981; Keul et al. 1982), and the three macronutrients were never compared simultaneously under the same conditions.

Since glucose is the predominant brain fuel, and the state of metabolic activation is a basic index for subsequent changes in brain neurotransmitter or hormone modulation, we expected the glucose metabolism as well as the state of metabolic activation to be related to postprandial cognitive changes. We therefore investigated, in an integrated design, baseline values and postprandial developments of subjective and objective psychological functions as well as concomitant metabolic and hormonal changes due to pure carbohydrate, protein or fat ingestion. Different cognitive functions were measured, and cognitive tests with different sensitivity were applied. To ensure comparable results for the individual macronutrients, three isoenergetic test meals, each consisting of only one macronutrient and similar in volume and sensory properties, were tested.

\section{Subjects and methods}

\section{Subjects}

Seventeen healthy male students, mean age $26 \cdot 5$ (SD 3.3) years, were recruited through advertisements posted at the Swiss Federal Institute of Technology and the University in Zurich. The subjects were informed about the general objectives, the procedure and possible risks of the study. All subjects gave their written informed consent to the study, which was approved by the ethical committee of the University Hospital Zurich. Subjects were compensated for their participation. They were non-smokers, not trained athletes, not colour-blind and had a mean BMI of 21.9 (SD 1.7) $\mathrm{kg} / \mathrm{m}^{2}$. They were not on any medication and did not take any drugs or nutritional supplements in the week before and during the experimental period. In addition, their nutritional habits and regular physical activity were recorded before the study. Results are reported for only fifteen subjects: one subject was excluded because of poor compliance, and one subject because we failed to obtain sufficient blood for metabolite and hormone analyses.

\section{Design and procedure}

The study was carried out according to a repeated-measures counterbalanced cross-over design. Subjects were tested in three sessions separated by exactly 1 week. They were told that various physiological and psychological effects of food intake were examined in the study, but they were not aware of ingesting different macronutrients. To avoid possible learning effects during the study that might have interfered with treatment effects, the subjects had to practise all cognitive tests on two separate days in the week before the experimental period. Thus, subjects also became familiar with the whole experimental procedure, which simulated a mild environmental stress situation of daily work.

To ensure similar baseline conditions, subjects were not allowed to ingest alcohol- or caffeine-containing drinks and foods, and they were requested to refrain from strenuous physical exercise during the day before each test. In addition, all subjects consumed an identical pre-packaged pasta meal between 19.00 and 21.00 hours on the evening before each test. This meal provided approximately $4400 \mathrm{~kJ}$ with $74 \%$ of the energy derived from carbohydrates, $11 \%$ from protein and $15 \%$ from fat. It consisted of fresh ravioli with a vegetarian filling $(250 \mathrm{~g})$, preserved tomato sauce $(300 \mathrm{~g})$, fresh carrot salad $(160 \mathrm{~g})$ and a canned fruit cocktail $(160 \mathrm{~g})$. The meal was rich in carbohydrates and scheduled late to avoid depleted liver glycogen stores the next morning. Subjects were instructed to ingest the whole meal and to have no further food or drinks except water until their test session the next morning. Subjects were also asked to sleep for at least $8 \mathrm{~h}$ if possible.

After a $10-12 \mathrm{~h}$ overnight fast, subjects arrived at the institute by public transport. Three subjects were tested daily, beginning at $7.00,7.15$ and 7.30 hours respectively (Fig. 1). Just after arrival, subjects had to fill out a questionnaire checking their compliance with the restrictions on the day before, as well as their sleep quality and their actual performance. Subsequently, electrodes for electromyography (EMG) measurements were attached to their forehead. Before the test meal, baseline (i.e. pre-meal) assessments were taken in the following order: 1, blood sampling; 2, respiratory measurements; 3 , questionnaires; 4, cognitive tests. Each of these assessments was scheduled for $15 \mathrm{~min}$. Subsequently, the cream-like test meal was served in a dessert bowl together with a spoon. Subjects had $10 \mathrm{~min}$ to eat the whole meal, and afterwards they had 5 min to fill out a questionnaire concerning its acceptance and its sensory properties. For repeated postprandial measurements within the next $3 \mathrm{~h}$ subjects had to rotate hourly through the same stations as under baseline

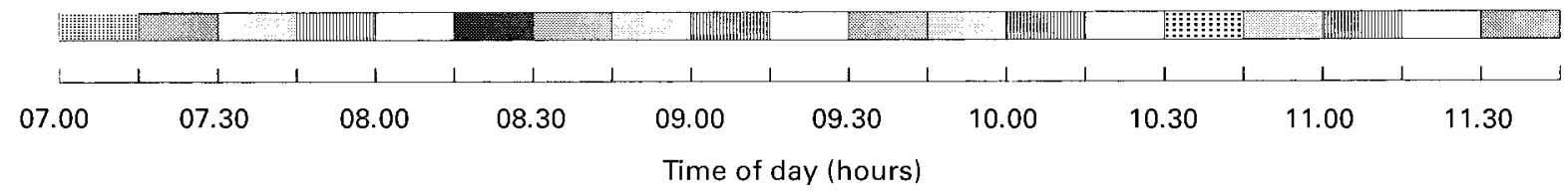

Fig. 1. Schedule of experimental procedures for the first subject on each test morning. Second and third subjects started 15 and 30 min later

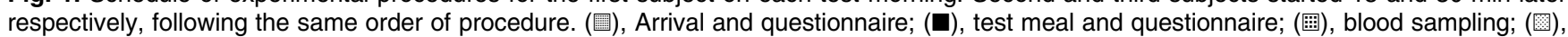
respiratory measurements; (四), questionnaires; $(\square)$, cognitive tests. 
Table 1. Composition $(\mathrm{g})$ of the three cream-like test meals*

\begin{tabular}{|c|c|c|}
\hline $\mathrm{ar}$ & & \\
\hline & $\begin{array}{l}4.7 \text { milk protein†† } \\
0.5 \text { dried chicken } \\
\text { g-white powder } \ddagger \ddagger\end{array}$ & 150.0 water \\
\hline \multicolumn{3}{|c|}{ 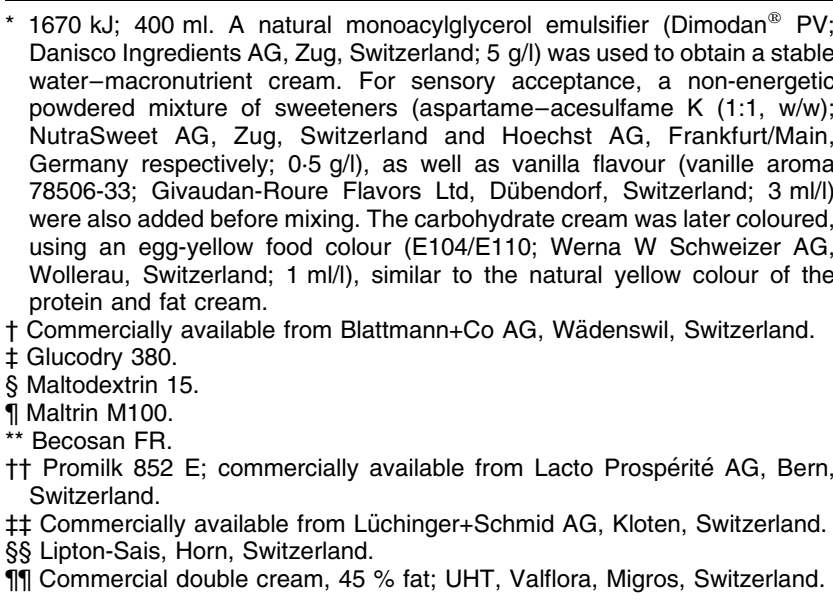 } \\
\hline
\end{tabular}

conditions. Subjects had free access to mineral water during the whole study, but no additional food or fluid intake was permitted.

\section{Test meals}

Test meals (Table 1) were isoenergetic (1670 kJ) emulsions or suspensions of only one macronutrient with similar volume and sensory properties, i.e. taste, texture and colour. They were freshly prepared by vigorous mixing (Bamix M 120; ESGE AG, Mettlen, Switzerland) of appropriate quantities of basic ingredients and water to obtain $400 \mathrm{ml}$ of a spoonable foam-like vanilla cream. Different basic ingredients from each macronutrient were used to ensure a broad spectrum of the representative compounds that might have differential effects on cognitive behaviour. The energy content of a test meal was in the range of the subjects' habitual energy intake for a morning. Acceptance and sensory homogeneity of the three test meals were tested by the staff of our institute before the study.

\section{Measurements}

Blood sampling and analyses. A 20-gauge vialon catheter (Insyte- $\mathrm{W}^{\circledR}$; Becton Dickinson, Rutherford, NJ, USA) was placed into the antecubital vein and fasting blood samples were drawn whilst the subject was in a lying position. The first $2 \mathrm{ml}$ of each blood sample was discarded. With the use of a multi-adapter, $2.6 \mathrm{ml}$ was collected into a NaF-containing tube (Monovette ${ }^{\circledR}$; Sarstedt AG, Sevelen, Switzerland) for later determination of plasma glucose and $\beta$-hydroxybutyrate (BHB). Another $12.4 \mathrm{ml}$ was collected into two EDTA-containing tubes
(Monovettes ${ }^{\circledR}$; Sarstedt AG, Sevelen, Switzerland) for analyses of further metabolites and hormones. For glucagon analysis, $1 \mathrm{ml}$ of the EDTA-treated blood sample was transferred into a glass tube containing $500 \mathrm{KIU}$ trypsin inhibitor (Aprotinin ${ }^{\circledR}$; Böhringer Mannheim $\mathrm{GmbH}$, Mannheim, Germany). All blood samples were immediately centrifuged $\left(1600 \mathrm{~g} ; 4^{\circ} \mathrm{C} ; 12 \mathrm{~min}\right)$, and plasma was stored at $-20^{\circ} \mathrm{C}$. Plasma for glucagon analysis was stored separately in glass tubes.

Plasma metabolites were analysed enzymically at $37^{\circ} \mathrm{C}$ (Cobas-Mira analyser; Roche, Basel, Switzerland). The following commercial kits were used: glucose and urea (Roche, Basel, Switzerland); fatty acids (Wako Chemicals $\mathrm{GmbH}$, Neuss, Germany); BHB (Sigma Diagnostics, St Louis, MO, USA). Hormones were analysed using commercially available radioimmunoassay kits: insulin (CIS Medipro SA, Geneva, Switzerland); cortisol and glucagon (Diagnostic Products Corporation, Los Angeles, CA, USA). The continuous nature of the experimental procedure did not allow assessment of meaningful macronutrient effects on plasma catecholamine concentrations. Thus, we used glucagon:insulin (G:I) as a more stable index of metabolic activation.

Respiratory measurements. The RER was determined during a 15 min period using a half-open system (Oxycon Sigma; Mijnhardt BV, Bunnik, The Netherlands). Subjects walked slowly on a treadmill $(2.5 \mathrm{~km} / \mathrm{h})$ to ensure stable respiration. Energy expenditure (EE) in terms of total thermogenesis was calculated according to the Weir (1949) formula.

Questionnaires. Sleep quality and mental as well as physical performance on the test mornings were rated using four-point rating scales. To record the acceptance, pleasantness and sensory homogeneity of the test meals, the following eleven (German) terms were used for the evaluation: quantity, tasty, sweet, insipid, pleasant, watery, filling, fatty, satiating, sticky and thirst provoking. As a result of greater reproducibility to usual visual analogue scales, answers were given by means of a sevenpoint bipolar equilateral rating scale ranging (in German) from 'not at all' $(-3)$ to 'extremely' (+3; Holt et al. 1995). The same kind of rating scale was used for the hourly questionnaires addressing the subjects' subjective performance. For this scale, eighteen different (German) terms (calm, relaxed, cold, clear-headed, tired, confused, cramped head, exhausted, feeling sick, nervous, heat, energetic, lively, receptive, stressed, efficient, thirsty, fullness) were used for the evaluation, with an equal number of positive and negative terms to reduce response bias (Mackay et al. 1978). In addition, an established computer-based German (Huber, 1994) questionnaire version (version 1.00; Dr G. Schuhfried GmbH, Mödling, Austria) of the profile of mood states (POMS) of McNair et al. (1971), which was shown to be sensitive to nutritional variables (Lieberman et al. 1985; Lloyd et al. 1994), was performed hourly (Fig. 1). Subjects had to rate thirty-five adjectives using seven-point rating scales on a monitor. These adjectives were clustered into the four principal mood factors: depression, fatigue, urge for action and ill-humour. The whole POMS ratings lasted approximately $2-3 \mathrm{~min}$. 
Cognitive performance tests. Different computer-based cognitive tasks, which have been shown to be sensitive to nutritional and environmental variables (Lieberman et al. 1985; Lloyd et al. 1994; Läubli et al. 1998), and an EMG measurement were performed to evaluate objective cognitive performance. The tests were arranged according to their expected increasing sensitivity to effects due to macronutrient ingestion. One session of tests lasted about $15 \mathrm{~min}$.

Simple and choice reaction time. Established versions of simple visual reaction time (simple RT) as well as choice visual and auditory reaction time (choice RT) were measured (Wiener Reaktionsgerät, version 8.00; Dr G. Schuhfried $\mathrm{GmbH}$, Mödling, Austria) as an easy reflex-like and more strenuous decision task respectively. In simple RT assessment, the subject had only to react to a yellow light by moving his finger as fast as possible from a rest contact button to a push-button, $5 \mathrm{~cm}$ further forward. In choice RT assessment, however, the subject had to react in the same manner to a yellow light that flashed either simultaneously with a red light or simultaneously with a tone. If the red light appeared simultaneously with a tone, or any of the signals appeared alone, the subject should not react. The whole reaction time was split into decision time and motor time, and for both, the mean reaction time as well as an error rate for each session were calculated. Simple RT and choice RT sessions lasted $2 \mathrm{~min}$ (twenty-eight signals) and $3 \mathrm{~min}$ (forty-eight signals) respectively.

Electromyography. EMG of the forehead was recorded during the choice RT as an index for the subjects' strain to fulfil a task. EMG signals were measured using three surface electrodes and amplified (Physio Recorder, version 1.01; Dr G. Schuhfried GmbH, Mödling, Austria). The mean muscle activity per session and the variation of the mean activity (as SD) were calculated.

Combi-test. A recently developed bimodal computerbased visual combi-test (Läubli et al. 1998) simulates complex cognitive tasks by simultaneously combining a demanding central short-term memory task and a simpler peripheral attention task. This design is believed to show a higher sensitivity compared with one-dimensional single task tests because the subject has to concentrate simultaneously on two tasks. The central short-term memory task consists of recognising defined sequences of coloured circles by pressing a button on a keyboard. These coloured circles are displayed in the middle of a $43 \mathrm{~cm}$ (17 in) monitor and appear one after another at the same place. In the additional peripheral attention task, the subject has to detect rotations of one of four patterned circles that are displayed at the corners of the same monitor by pressing another button on the keyboard. A qualitative accuracy score (correct responses in given responses) as well as a quantitative efficiency score (correct responses in demanded responses) were calculated from the central short-term memory task. Similarly, a qualitative attention score as well as a quantitative efficiency score were calculated for the peripheral task. The mean reaction time was determined for the central and peripheral task. From these single subscores, a total score was calculated:

$$
\begin{aligned}
\text { total score }= & (\text { central qualitative score } \\
& \times \text { central quantitative score } \\
& \times 100 / \text { central reaction time }) \\
& +(\text { peripheral qualitative score } \\
& \times \text { peripheral quantitative score } \\
& \times 100 / \text { peripheral reaction time })
\end{aligned}
$$

The whole test lasted 5 min per session.

\section{Statistical analyses}

Statistical analyses were performed with Systat software (version 7.0.1; SPSS Inc., Chicago, IL, USA). Arcsine transformation was applied for the percentage scores of the combi-test to adjust for the general linear model. Using a split-plot model (Schlich, 1993), independent variables were the subject, the period of the test day and the type of macronutrient (main unit), as well as the timing of the repeated measurements during the test morning (split unit). The period was included in the model to control for learning effects between test days. Data were adjusted for baseline measurements by including absolute values of pre-meal measurements as covariates in the model. Repeatedmeasures ANOVA with treatment as a grouping factor and time as a within factor was performed to detect overall meal effects, meal $\times$ time interactions or time main effects. For significant overall differences between treatments, the data were further analysed with Tukey's post hoc comparisons. Polynomial contrast analysis was performed for significant meal $\times$ time interactions and time main effects. To analyse the relationship between overall postprandial metabolic and cognitive indices, simple and multiple correlation and regression analyses as well as interactive stepwise modelling were applied. Statistical significance was set at $P<$ 0.05. Data are presented as means with standard errors of the means and as arcsine transformed means with standard errors of the means for scores of the combi-test.

\section{Results}

\section{Postprandial metabolic and hormonal changes}

There were highly significant overall meal $(P<0.001)$ as well as meal $\times$ time $(P<0.001 ; P<0.05$ for glucagon $)$ effects for all plasma metabolite and hormone concentrations, except for cortisol.

Glucose, insulin and glucagon. For the fat meal the plasma glucose, insulin and glucagon concentration, as well as the G:I, remained approximately constant over time (Fig. 2). There were, however, significant changes over time for the same indices after the carbohydrate meal, resulting in a significant quadratic response for the G:I $(P<0.01)$. In contrast, after the protein meal, only the glucagon concentration changed significantly over time $(P<0.001)$. Glucagon transiently increased compared with the transient decrease after the carbohydrate meal, 
(a) Glucose

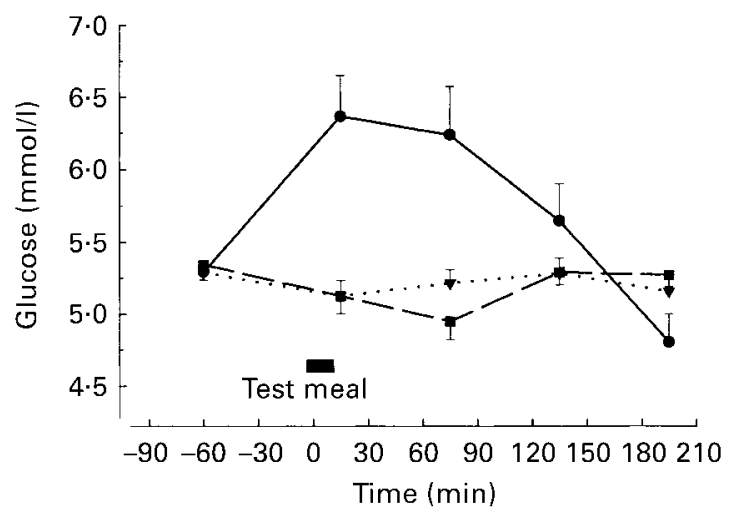

(c) Glucagon

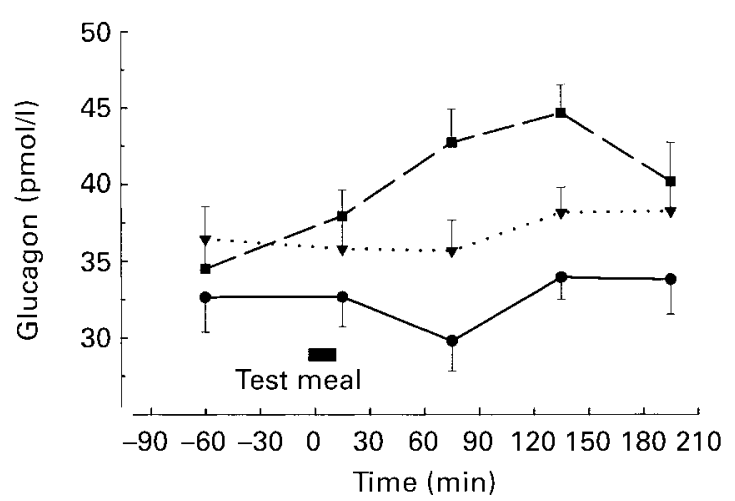

(b) Insulin

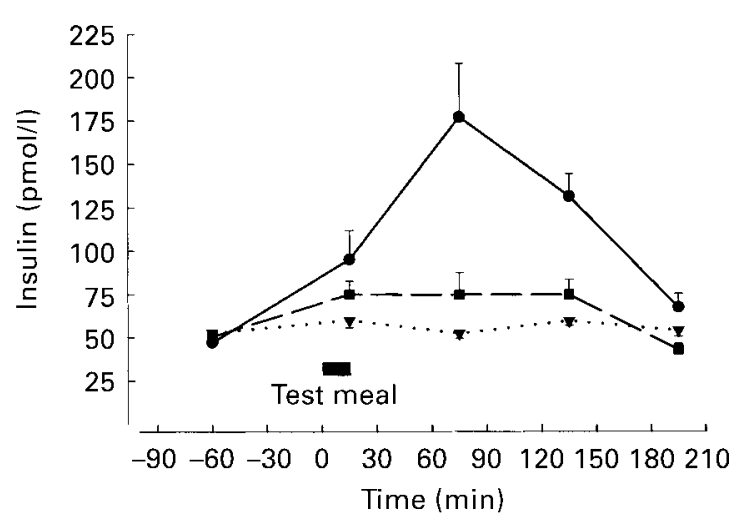

(d) Glucagon:insulin

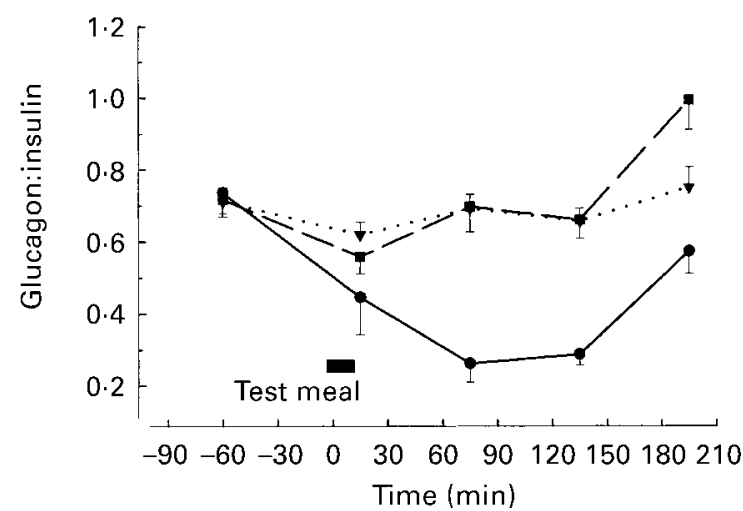

Fig. 2. Temporal profiles for (a) glucose, (b) insulin and (c) glucagon responses as well as for the (d) glucagon:insulin to pure carbohydrate (CHO; $\boldsymbol{0}$ ), protein ( $\mathbf{\square})$ or fat $(\mathbf{\nabla})$ ingestion (for details of test meals and procedures, see Table 1 and p. 395). Values are means with standard errors of the means represented by vertical bars for fifteen subjects. Test meal ingestion ( $0-15 \mathrm{~min})$ and postprandial temporal pattern of changes (15$195 \mathrm{~min}$ ) were preceded by a baseline $(-60 \mathrm{~min}$ ) measurement. For glucose, insulin and glucagon:insulin the overall effect of the $\mathrm{CHO}$ meal was significantly different from those of the protein and fat meals (Tukey's post hoc comparisons; $P<0.001$ ). For glucagon the overall effect of the fat meal was significantly different from those of the $\mathrm{CHO}$ and protein meals $(P<0.01)$, and the overall effect of the $\mathrm{CHO}$ meal was significantly different from that of the protein meal $(P<0.001)$. The meal $\times$ time interactions were significant: for glucose, insulin, glucagon:insulin $P<0.001$; for glucagon $P<0.05$. Trends for meal $\times$ time interactions were significant (polynomial contrast analysis): for glucose, linear trend $P<0.001$; for insulin, glucagon and glucagon:insulin, quadratic trend $P<0.01, P<0.01$ and $P<0.001$ respectively.

resulting in a stepwise rise in G:I that was higher than that after carbohydrate ingestion.

Fatty acids, $\beta$-hydroxybutyrate, urea and cortisol. There was a significant linear increase for the fatty acid concentration as well as for the BHB concentration after the fat meal $(P<0.001$; Fig. 3). After the carbohydrate and protein meals, however, the fatty acid concentration first decreased and only later rose again. The BHB concentration decreased after the carbohydrate meal, but remained approximately constant after the protein meal. Urea concentration significantly increased only after the protein meal $(P<0 \cdot 001)$, whereas it slightly decreased after carbohydrate and fat ingestion. For cortisol there was only a significant time main effect $(P<0.05)$, resulting in a continuous linear decrease in cortisol concentration with time for all test meal conditions.

\section{RER and energy expenditure}

There was a significant overall meal effect $(P<0.0001)$ as well as meal $\times$ time effect $(P<0.001)$ for the RER and a significant overall meal effect for $\mathrm{EE}(P<0 \cdot 01$; Table 2$)$. After the carbohydrate meal there was an intense and significant linear increase in the RER, which exceeded the value 1.0 in the second hour. However, after the fat and protein meals the RER remained approximately at baseline values. Overall EE was significantly lower after the fat meal than after the carbohydrate or protein meals.

\section{Questionnaire data}

The compliance of the subjects with the restrictions during the last $24 \mathrm{~h}$ before their experimental day did not differ significantly between treatments. Sleep quality and subjects' mental as well as physical performance on the test mornings were also not significantly different between treatments. Furthermore, the acceptance and sensory impression of the test meals did not differ significantly. However, the acute 'filling' (Tukey's post hoc comparison; $P<0.01$ ) and 'satiating' (Tukey's post hoc comparison; 
(a) Fatty acids

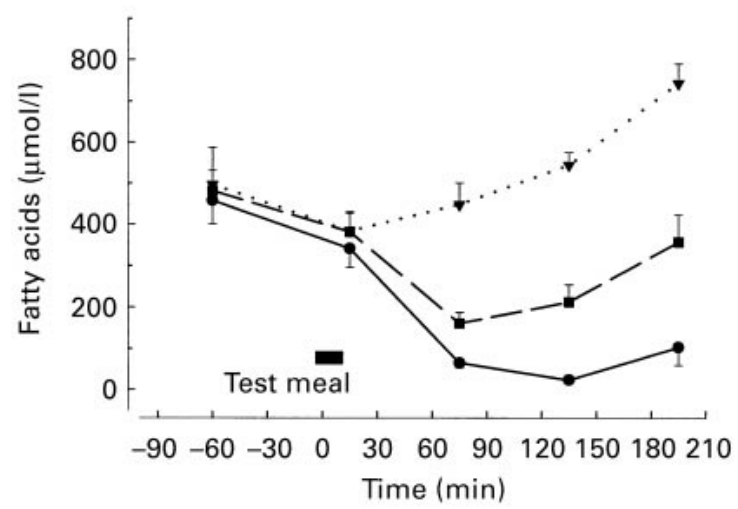

(c) Urea

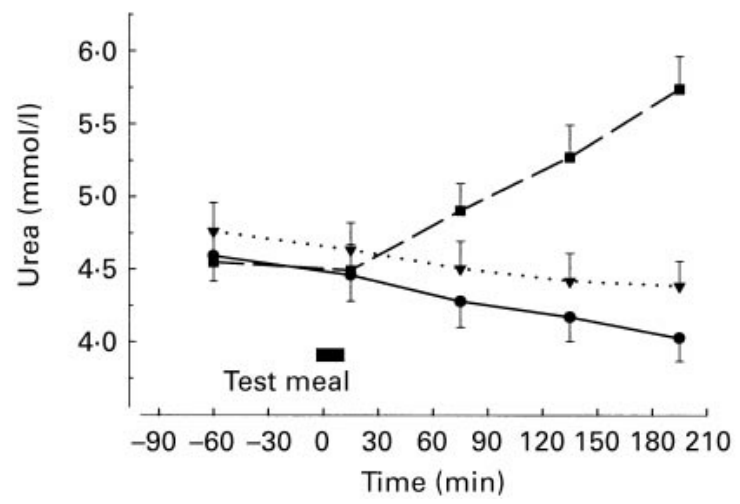

(b) B-hydroxybutyrate

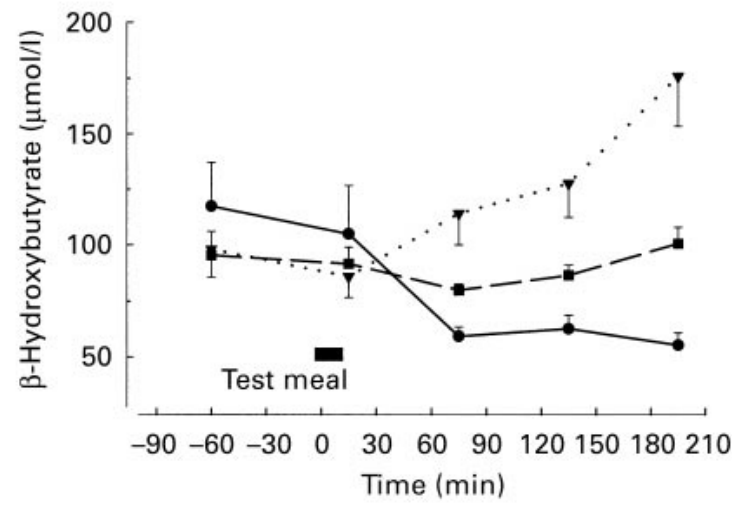

(d) Cortisol

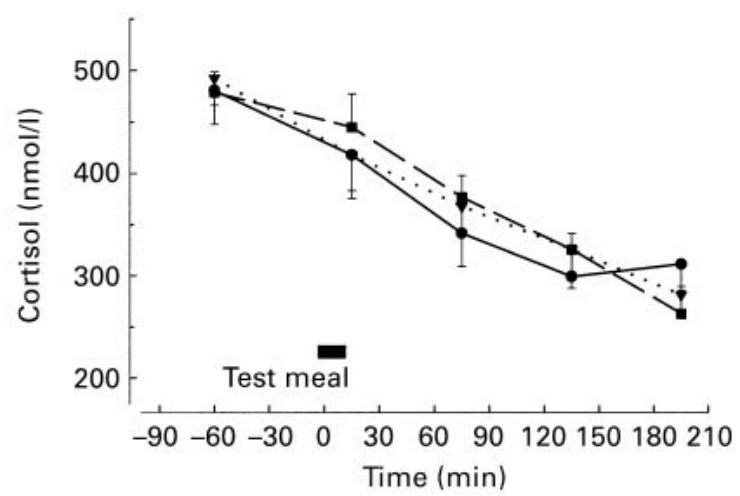

Fig. 3. Temporal profiles for (a) fatty acids (b) $\beta$-hydroxybutyrate, (c) urea and (d) cortisol responses to pure carbohydrate (CHO; $\bullet$ ), protein ( $\square$ ) or fat $(\mathbf{\nabla})$ ingestion (for details of diets and procedures, see Table 1 and p. 395). Values are means with standard errors of the means represented by vertical bars for fifteen subjects. Test meal ingestion (0-15 $\mathrm{min}$ ) and postprandial temporal pattern of changes (15-195 min) were preceded by a baseline $(-60 \mathrm{~min})$ measurement. For fatty acids and $\beta$-hydroxybutyrate, the overall effect of the fat meal was significantly different from those of the $\mathrm{CHO}$ and protein meals (Tukey's post hoc comparisons; $P<0.001$ and $P<0.01$ respectively). For fatty acids the overall effect of the $\mathrm{CHO}$ meal was significantly different from that of the protein meal $(P<0.01)$. For urea the overall effect of the protein meal was significantly different from those of the $\mathrm{CHO}$ and fat meals $(P<0.001)$. The meal $\times$ time interactions for fatty acids, $\beta$-hydroxybutyrate and urea were significant $(P<0.001)$. The time mean effect for cortisol was significant $(P<0.05)$. The linear trend for the meal $\times$ time interaction was significant (polynomial contrast analysis) for fatty acids, $\beta$-hydroxybutyrate and urea $(P<0.001)$. The linear trend for the time mean effect for cortisol was significant $(P<0.05)$.

Table 2. Temporal changes for the RER as well as for energy expenditure (EE) after pure carbohydrate, protein or fat ingestion in fifteen healthy young men*

(Values are means with the standard errors of the means)

\begin{tabular}{|c|c|c|c|c|c|c|c|c|c|c|}
\hline \multirow{2}{*}{$\begin{array}{l}\text { Time of repeated } \\
\text { measurements }(\min ) \dagger \ldots\end{array}$} & \multicolumn{2}{|c|}{-45} & \multicolumn{2}{|c|}{30} & \multicolumn{2}{|c|}{90} & \multicolumn{2}{|c|}{150} & \multicolumn{2}{|c|}{$\begin{array}{l}\text { Statistical significance of effects } \\
\text { (repeated-measures ANOVA: } P=\end{array}$} \\
\hline & Mean & $\overline{\text { SEM }}$ & Mean & $\overline{\text { SEM }}$ & Mean & $\overline{\text { SEM }}$ & Mean & $\overline{\text { SEM }}$ & Meal & Meal $\times$ time \\
\hline \multicolumn{11}{|l|}{ RER } \\
\hline Carbohydrate meal & 0.88 & 0.01 & 0.96 & 0.02 & 1.02 & 0.09 & 1.04 & 0.09 & & \\
\hline Protein meal & 0.90 & 0.02 & 0.91 & 0.01 & 0.92 & 0.01 & 0.92 & 0.01 & $0.0001 \ddagger$ & 0.001 \\
\hline Fat meal & $0 \cdot 88$ & 0.01 & 0.91 & 0.01 & 0.89 & 0.01 & 0.90 & 0.02 & & \\
\hline \multicolumn{11}{|l|}{$\mathrm{EE}(\mathrm{kJ} / \mathrm{min})$} \\
\hline Carbohydrate meal & $14 \cdot 3$ & 0.52 & 14.5 & 0.49 & $13 \cdot 8$ & 0.44 & 13.7 & 0.41 & & \\
\hline Protein meal & 13.9 & 0.59 & $14 \cdot 3$ & 0.68 & 13.9 & 0.53 & $13 \cdot 8$ & 0.54 & $0.01 \neq$ & NS \\
\hline Fat meal & $13 \cdot 8$ & 0.41 & 13.5 & 0.51 & $13 \cdot 1$ & 0.51 & $13 \cdot 2$ & 0.47 & & \\
\hline
\end{tabular}

${ }^{*}$ For details of test meals and procedures, see Table 1 and p. 395.

† Test meal ingestion (0-15 min) and postprandial temporal pattern of changes (30-150 min) are preceded by a baseline ( -45 min) measurement.

$\ddagger$ Overall meal effects were significant (Tukey's post hoc comparisons): for RER carbohydrate $>$ protein and fat $(P<0.001)$; for EE protein $>$ fat $(P<0.05)$. 

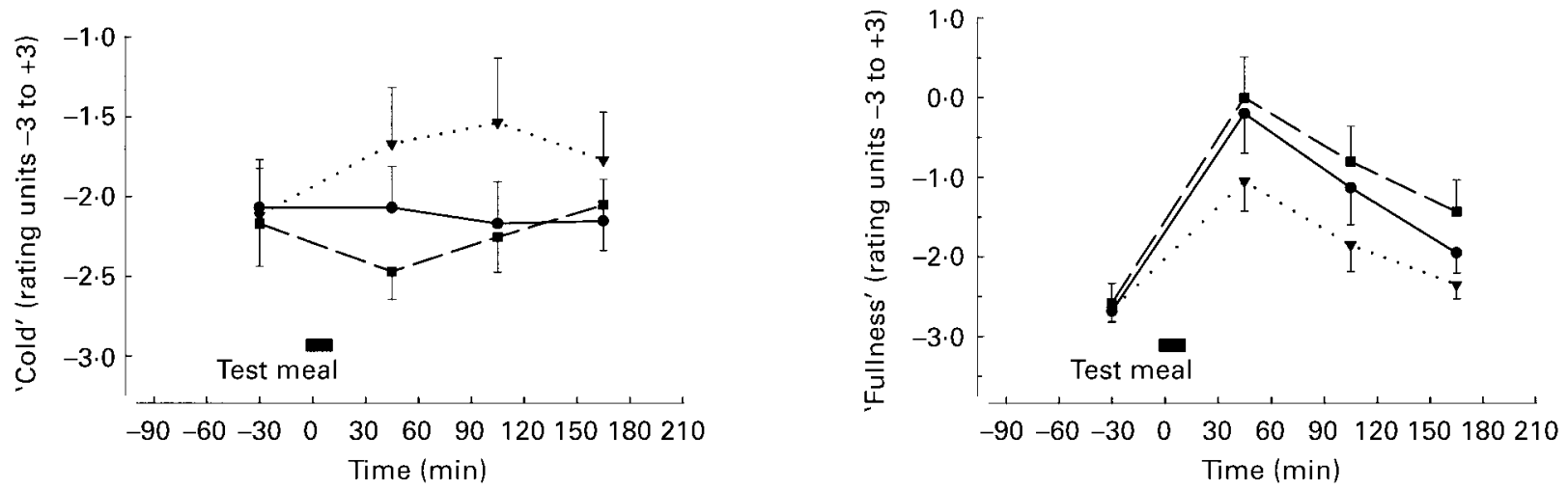

Fig. 4. Temporal profiles for subjective 'cold' and 'fullness' ratings to pure carbohydrate $(\boldsymbol{\bullet})$, protein $(\boldsymbol{\square})$ or fat $(\mathbf{\nabla})$ ingestion (for details of test meals and procedures, see Table 1 and p. 395). Values are means with standard errors of the means represented by vertical bars for fifteen subjects. Test meal ingestion (0-15 $\mathrm{min})$ and postprandial temporal pattern of changes (45-165 min) were preceded by a baseline ( -30 min) measurement. The overall effect of the fat meal was significantly different from that of the protein meal (Tukey's post hoc comparisons: for 'cold' $P<0.05$, for 'fullness' $P<0.01$.

$P<0 \cdot 01)$ ratings were significantly higher immediately after the protein meal compared with the carbohydrate or fat meal, and the fat meal was rated as more watery (Tukey's post hoc comparison; $P<0.01$ ) in comparison with the other two meals (data not shown). For most terms used for assessment the ANOVA results from data concerning the subjects' hourly subjective performance, as well as the four principal mood factors of the POMS, no overall meal effect or meal $\times$ time interaction were detected. However, overall 'cold' ratings were significantly higher after the fat meal compared with the protein meal $(P<0.05)$, whereas ratings for overall 'fullness' were significantly higher after the protein meal compared with the fat meal $(P<0.01$; Fig. 4). Overall ratings for 'depression' (Tukey's post hoc comparison; $P<0.05$ ) of the POMS were significantly lower after the carbohydrate meal in comparison with the protein meal (data not shown).
Significant time main effects were seen for the ratings of 'energetic', and similar for 'efficient', 'fatigue' and 'urge for action' (data not shown), reflecting a decrease in performance in the second hour for all test meals (ANOVA; $P<0 \cdot 05)$.

\section{Cognitive performance data and scores}

There was no significant effect for the period of the experimental day for all tasks, indicating that there were no learning effects between test days. ANOVA results for cognitive performance data are summarised in Table 3.

Simple and choice reaction and electromyography. Simple RT measurements showed no significant meal or meal $\times$ time effects, but there was a significant linear time main effect $(P<0 \cdot 01)$ for the motor reaction time (Table 3 ). For the decision time and the error rate of choice RT,

Table 3. F-ratios and statistical significance of repeated-measures ANOVA for objective cognitive performance tasks and measurements in fifteen healthy young men after pure carbohydrate, protein or fat ingestion $\dagger$

\begin{tabular}{|c|c|c|c|}
\hline Objective performance tasks & Meal effectł (df 2, 25) & Time effect§ (df 2, 50) & Meal $\times$ time effect§ $($ df 4,50$)$ \\
\hline \multicolumn{4}{|l|}{ Simple reaction time } \\
\hline Motor time & 0.08 & $7.52^{\star \star \star}$ & 0.42 \\
\hline Decision time & 0.12 & 0.25 & 0.44 \\
\hline \multicolumn{4}{|l|}{ Choice reaction time } \\
\hline Motor time & 0.20 & 1.35 & 0.04 \\
\hline Decision time & 2.34 & 0.04 & $2.85^{\star}$ \\
\hline Error rate & 0.09 & 0.33 & $2.72^{*}$ \\
\hline \multicolumn{4}{|l|}{ Electromyography } \\
\hline Mean muscle activity & 0.05 & 0.16 & 0.21 \\
\hline Variation in muscle activity & 1.09 & $5.04^{*}$ & 1.33 \\
\hline \multicolumn{4}{|l|}{ Combi-test } \\
\hline Central reaction time & 0.46 & 0.84 & $4.01^{*}$ \\
\hline Peripheral reaction time & 1.22 & 0.06 & 2.52 \\
\hline Accuracy in central short-term memory & $8.15^{\star \star}$ & 0.41 & 1.48 \\
\hline Central efficiency & $4.02^{*}$ & 0.66 & 0.33 \\
\hline Accuracy in peripheral attention & $3.48^{*}$ & 1.95 & 0.41 \\
\hline Peripheral efficiency & 0.01 & 2.18 & 1.79 \\
\hline Total score & $3.41^{*}$ & 0.12 & 1.81 \\
\hline
\end{tabular}

${ }^{\star} P<0.05,{ }^{\star \star} P<0.01,{ }^{\star \star \star} P<0.001$.

† For details of test meals and performance tasks and measurements, see Table 1 and p. 395.

‡ Main unit error.

$\S$ Split unit error. 
however, a significant meal $\times$ time interaction was detected $(P<0 \cdot 05)$. Comparing the carbohydrate with the protein meal, the time course of these two scores was inversely related (Fig. 5). This relationship was particularly pronounced for the error rate of choice RT. There was no significant effect of the test meals on EMG data, but the variation in EMG signals significantly changed with time (ANOVA; $P<0.001$ ), i.e. increased after the second hour (data not shown).

Combi-test. Reaction times of the simpler peripheral task did not differ significantly between meals (Table 3). Reaction times of the demanding central task, however, showed a significant meal $\times$ time effect $(P<0 \cdot 01$; Fig. 6). Temporal patterns of changes were different for the carbohydrate and protein meal, in particular after the second hour.

For the central short-term memory, as well as for the peripheral attention task and the total score, significant overall meal effects were detected $(P<0.01$ and $P<0.05$ respectively; Table 3 ). In all cases, subjects reached the highest scores after the fat meal (Fig. 6). For the accuracy in central short-term memory overall scores were significantly different (fat $>$ carbohydrates $>$ protein). However, overall scores for the central efficiency as well as the accuracy in peripheral attention were in the order fat $>$ protein $>$ carbohydrates, with a significant difference between the fat and the carbohydrate meals $(P<0.05)$. Total scores were significantly higher (Tukey's post hoc comparison; $P<0.05$ ) after the fat meal (mean 86.7 (SEM 6.13)) than after the carbohydrate meal (mean $77 \cdot 1$ (SEM $5.53)$ ) or protein meal (mean 78.4 (SEM 5.61)) with no significant difference between the carbohydrate and protein meals.

\section{Correlation and regression analyses}

Correlation or regression analyses did not reveal any significant relationship between single metabolic indices and cognitive functions. However, using stepwise multiple regression or canonical correlation for overall scores of the combi-test, cognitive functions correlated significantly with sets of metabolic indices including the overall G:I, glucose and/or urea, or cortisol concentration (Table 4).

\section{Discussion}

We report here significant effects of pure macronutrient ingestion on different cognitive functions, with the best performance usually observed after fat ingestion. Sets of metabolic indices, including the G:I, could be related to different cognitive functions. Cognitive behaviour depends on a variety of factors (Kanarek, 1997), including preabsorptive signals (Diamond \& LeBlanc, 1988; Rogers, 1995). However, as energy content, volume, acceptance and sensory properties of our test meals were matched, the observed effects on metabolic and cognitive indices could be attributed to the type of macronutrient ingested (Craig, 1986). The subjects (young male students) were tested in the morning after an overnight fast, but their glycogen stores were probably not depleted because they had eaten a carbohydrate-rich meal on the evening before the test day.
The energy content of the test meals is also important for interpretation, because opposite effects on a letter cancellation task, i.e. reduced or increased error rates, were reported for a $1250 \mathrm{~kJ}$ and $4000 \mathrm{~kJ}$ test meal respectively (Craig, 1986). The ingestion of our $1670 \mathrm{~kJ}$ test meals caused metabolic changes within the usual physiological range. Thus, it was expected and confirmed by our results that only highly sensitive tests could detect significant cognitive effects attributed to the test meal ingestion. The $3 \mathrm{~h}$ postprandial interval used to evaluate the effect of a $1670 \mathrm{~kJ}$ meal on cognitive performance is appropriate, assuming that digestion and absorption have almost ceased by then and that the next meal or snack is usually imminent.

\section{Subjective state}

Subjective ratings of 'energetic' and 'efficient' as well as forehead muscle activity were not influenced by macronutrient ingestion, but performance decreased shortly before 12.00 hours, presumably related to the circadian rhythm. In contrast, we found no time influence on any of the demanding objective performance tasks, although these tasks revealed effects of macronutrient ingestion. Thus, subjective performance estimates do not necessarily reflect objective cognitive performance. This finding is also supported by previous findings (De-Feo et al. 1988; Fery et al. 1997; Paz \& Berry, 1997). In line with the findings of another study (Lloyd et al. 1994) in which postprandial subjective performance was recorded for $3 \mathrm{~h}$, only few of the subjective ratings in our study were influenced by macronutrient ingestion. The weaker feelings for 'cold' and stronger feelings for 'fullness' after the protein meal compared with the fat meal could be explained by the higher thermogenesis (as indicated by the higher EE) and the specific satiating effect of protein (Porrini et al. 1997) respectively. The smaller depression scores reported here after the carbohydrate meal compared with the protein meal were also observed after carbohydrate ingestion in women with premenstrual depression (Wurtman et al. 1989; Sayegh et al. 1995), and are commonly explained by a carbohydrate-induced increase in the synthesis of brain serotonin (Fernstrom \& Wurtman, 1972). In contrast, protein ingestion is assumed to decrease brain serotonin and to facilitate brain catecholamine synthesis by precursor supply, resulting in a more alert and tense state (Wurtman \& Fernstrom, 1975; Fernstrom, 1977; Lieberman et al. 1986).

\section{Objective performance}

The sedative-like effect of carbohydrate ingestion as well as the arousing effect of protein ingestion have also been found to influence reaction times. Unlike studies that reported slower reaction times for simple visual (Cunliffe et al. 1997) or auditory (Lieberman et al. 1986) reactions after carbohydrate ingestion, we could not detect any negative effect of carbohydrate ingestion on simple RT and on the peripheral reaction time of the combi-test. Simple RT, however, was presumably not sensitive enough to detect differences between our test meals because the decision to react is a simple positive or negative one. For 
(a) Decision time of choice reaction

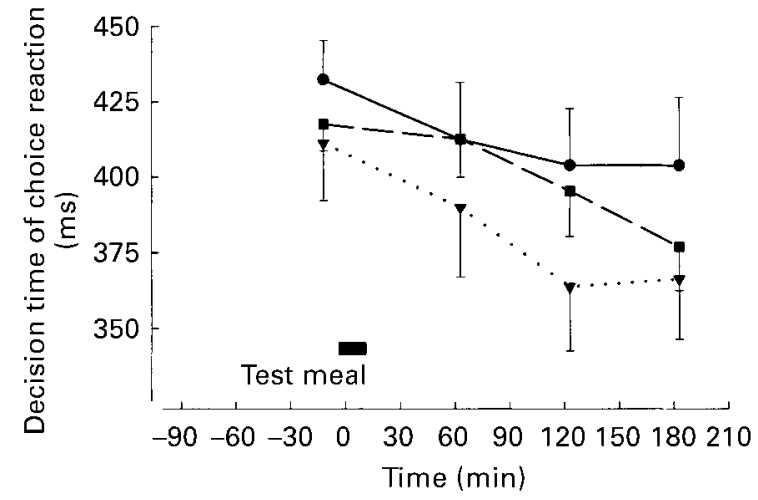

(b) Error rate of choice reaction

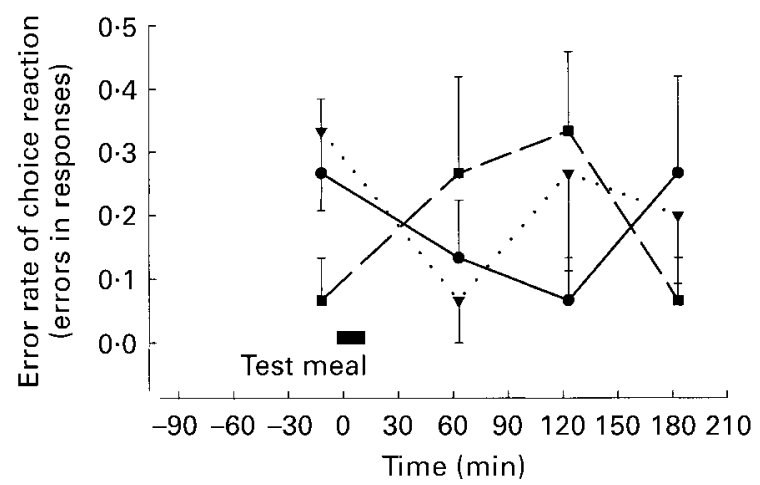

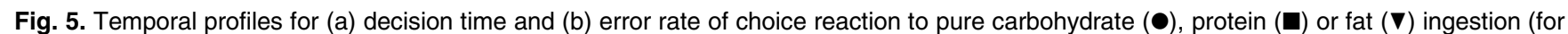
details of test meals and procedures, see Table 1 and p. 395). Values are means with the standard errors of the means represented by vertical bars for fifteen subjects. Test meal ingestion $(0-15 \mathrm{~min})$ and postprandial temporal pattern of changes $(60-180 \mathrm{~min})$ were preceded by a baseline $(-15 \mathrm{~min})$ measurement. The meal $\times$ time interactions were significant $(P<0.05)$. The linear trend for the meal $\times$ time interaction (polynomial contrast analyses) was significant for decision time of choice reaction $(P<0.05)$.

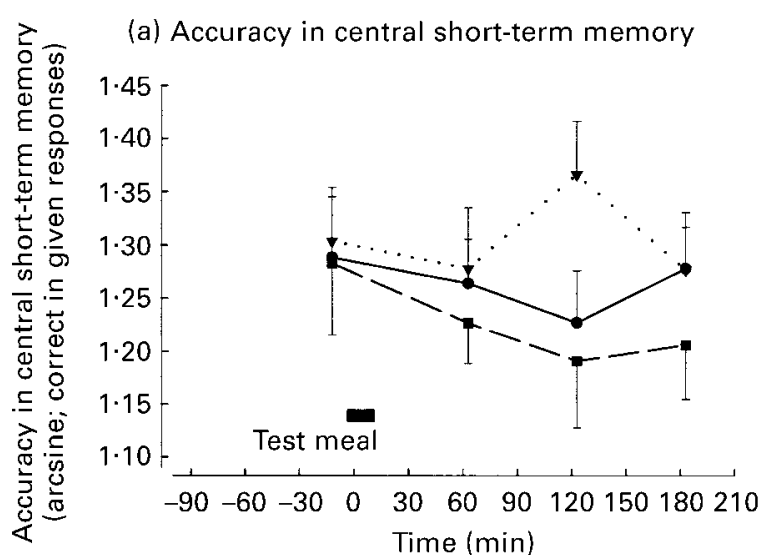

(c) Accuracy in peripheral attention

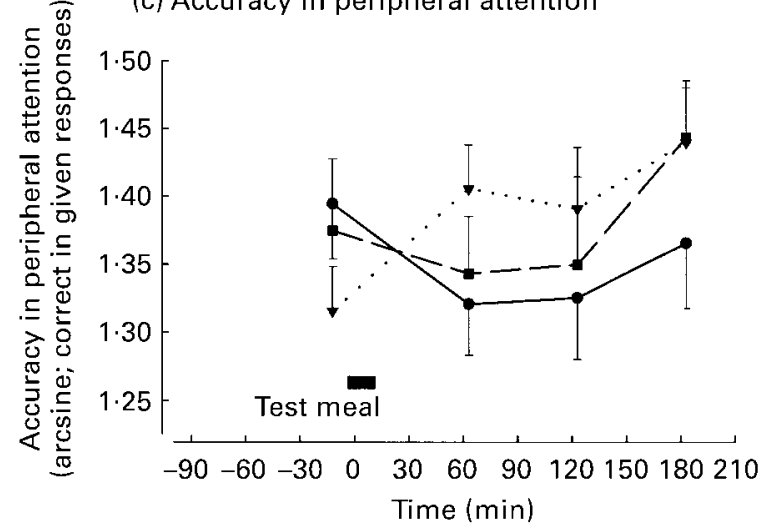

(b) Central efficiency

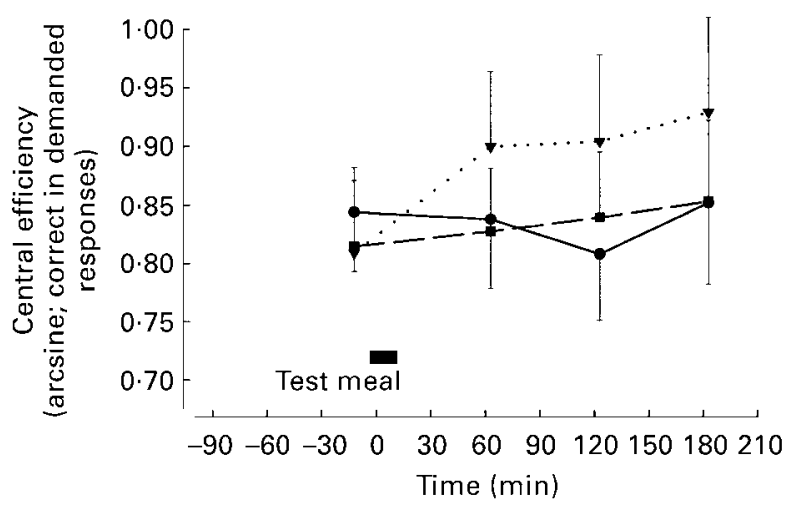

(d) Central reaction time

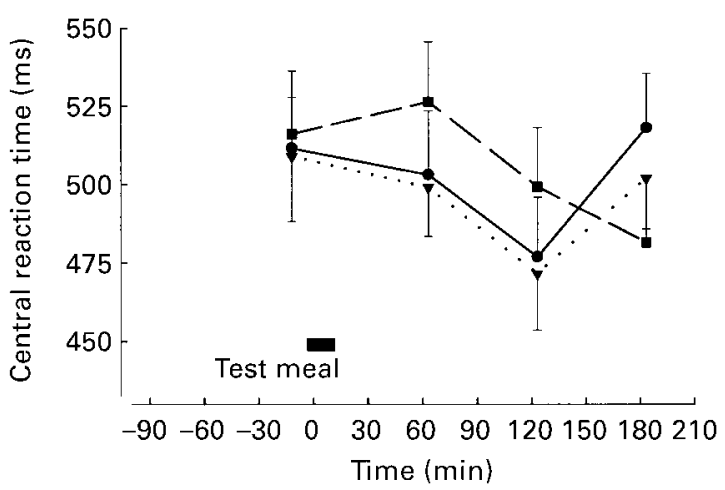

Fig. 6. Temporal profiles for arcsine-transformed (a) central short-term memory, (b) central efficiency and (c) peripheral attention scores, as well as for (d) reaction times of the central task of the combi-test to pure carbohydrate (CHO; $\boldsymbol{\bullet})$, protein $(\boldsymbol{\square})$ or fat $(\mathbf{\nabla})$ ingestion (for details of test meals and procedures, see Table 1 and p. 395). Values are means with the standard errors of the means represented by vertical bars for fifteen subjects. Test meal ingestion ( $0-15 \mathrm{~min})$ and postprandial temporal pattern of changes $(60-180 \mathrm{~min})$ were preceded by a baseline ( $-15 \mathrm{~min})$ measurement. For accuracy in central short-term memory the overall effect of the $\mathrm{CHO}$ meal was significantly different from that of the protein meal (Tukey's post hoc comparisons; $P<0.05$ ) and the overall effect of the fat meal was significantly different from those of the $\mathrm{CHO}$ and protein meals $(P<0.01)$. For central efficiency and accuracy in peripheral attention the overall effect of the fat meal was significantly different from that for the $\mathrm{CHO}$ meal $(P<0.05)$. For central reaction time the meal $\times$ time effect and the linear trend for the effect of meal $\times$ time $($ polynomial contrast analyses) were significant $(P<0.01)$. 
Table 4. Statistics for the most important independent metabolic variables of multiple stepwise regression and the respective canonical correlation for overall cognitive functions of the combi-test for fifteen healthy young men

\begin{tabular}{|c|c|c|c|}
\hline Type of cognitive function & Short-term memory & Central efficiency & Peripheral attention \\
\hline \multicolumn{4}{|l|}{ Multiple regression† } \\
\hline \multicolumn{4}{|l|}{ Coefficients } \\
\hline glucagon:insulin & $0.27^{\star}$ & $0.18^{\star *}$ & $0 \cdot 24^{\star \star \star}$ \\
\hline glucose & 0.06 & - & - \\
\hline urea & $-0.07^{*}$ & $-0.06^{*}$ & $-0.05^{\star \star}$ \\
\hline cortisol & - & - & $0.001^{*}$ \\
\hline Squared multiple $\mathrm{R}$ & 0.81 & 0.95 & 0.89 \\
\hline F-statistic $\neq$ & $6 \cdot 7^{\star \star \star}$ & $30 \cdot 6^{* \star \star}$ & $12 \cdot 0^{\star \star \star}$ \\
\hline Canonical correlation§ & 0.97 & 0.95 & 0.96 \\
\hline
\end{tabular}

${ }^{*} P<0.05,{ }^{* *} P<0.01,{ }^{* *} P<0.001$

† Variables were removed from the model if $P>0.15$ for the respective regression coefficients. Subject $(P<0.001)$ as additional independent variable was included in the model.

\pm F-statistic of ANOVA for the whole regression model.

$\S$ Same set of independent variables as listed for the respective multiple regression.

the more demanding choice RT and the central reaction of the combi-test, a worsened reaction for the carbohydrate meal and an improved reaction for the protein meal was seen only after the second hour, whereas the reverse was true for the first hour, i.e. the carbohydrate meal improved the reaction time, whereas the protein meal worsened it. This finding may be explained by the positive effect of glucose supply on brain function (Parsons \& Gold, 1992; Gold, 1995) immediately after carbohydrate ingestion and/ or by delayed neurotransmitter synthesis after test meal ingestion. Similarly, decision time in the morning was reported to be improved about $15 \mathrm{~min}$ after glucose supply, but only if blood glucose concentration rose concomitantly with measurements (Owens \& Benton, 1994). Together, these findings indicate that the time interval for different mechanisms influencing cognitive behaviour after macronutrient ingestion can vary. Thus, the whole postprandial metabolic profile instead of just one individual time point must be measured for an overall assessment of macronutrient effects on cognitive performance. Cunliffe et al. (1997) reported that a pure fat meal did not increase reaction times in contrast to carbohydrate ingestion when measured hourly for $4 \mathrm{~h}$ after the meal. In our study, fat ingestion even improved reaction times compared with baseline.

Our subjects scored best for all tasks of the combi-test after the fat meal. This finding is in line with the higher accuracy of a focused attention task after a high-fat meal compared with a low-fat meal reported by others (Smith et al. 1994). We also recorded better accuracy in short-term memory as well as a lower error rate for the choice RT after carbohydrate than after protein ingestion, whereas the opposite was true for the central efficiency as well as for the accuracy in peripheral attention. This finding is consistent with the suggested trade-off between accuracy and efficiency (Pollitt et al. 1981; Spring et al. 1982; Smith et al. 1994), i.e. between the qualitative or quantitative indices to evaluate a cognitive task, and the trade-off between central and peripheral performance (Smith et al. 1988). However, these differences in the subscores became level for carbohydrates and protein with regard to the total score of the combi-test, and both resulted in lower total cognitive performance than after fat ingestion.

\section{Metabolic changes}

After fat ingestion, only the plasma concentrations of fatty acids and BHB were increased, whereas the other physiological indices did not change over time. There were, however, marked changes in most metabolic indices after carbohydrate and protein ingestion. Since the brain is very sensitive to changes in nutrient supply, even small metabolic changes might influence behaviour, whereas constant conditions might stabilise behaviour and optimise performance (Santucci et al. 1990). In line with this assumption, an 'inverted U'-shaped dose-response relationship is usually observed for the effect of drugs or hormones on cognitive performance (Cahill \& McGaugh, 1996). It implies that performance has an optimum at a certain central or peripheral concentration of these influencing factors and worsens below or above this optimal concentration. This factor might explain why we found that overall performance was best for the constant plasma concentrations of glucose, insulin and glucagon after fat ingestion and increased or decreased after carbohydrate or protein ingestion respectively. An 'inverted U'-shaped response curve was reported for the influence of glucose on cognitive performance (Holmes, 1987), consistent with an impairment of cognitive function for acute hypoglycaemia (De-Feo et al. 1988; Stevens et al. 1989) as well as hyperglycaemia (Davis et al. 1996). In line with these findings, performance was best for all scores of the combi-test with the approximately stable plasma glucose concentration after fat ingestion in our study and worsened with an increase or decrease in plasma glucose concentration after carbohydrate or protein ingestion respectively. The absolute level of such an optimal concentration is presumably individually variable and within a range rather than a particular value (Holmes, 1987; Parsons \& Gold, 1992; Owens \& Benton, 1994). In addition, changes in blood glucose concentration, but not absolute levels, seem to be critical for a modulation of cognitive functioning (Santiago et al. 1980; Owens \& Benton, 1994).

Metabolism after fat ingestion. Pollitt et al. (1981) reported improved cognition in children during a short fasting state compared with breakfast ingestion. They discussed an integrated homeostatic metabolism during this 
situation of light metabolic stress, ensuring a constant blood glucose concentration. This homeostatic fasting state was characterised by increased plasma concentrations of plasma fatty acids, BHB, glucagon and catecholamines, and by a decreased plasma insulin concentration, thus reflecting a state of mild arousal. Metabolic indices after the fat meal in our study suggested a similar metabolic state. Filled liver glycogen stores presumably provided a constant glucose supply for the brain after the overnight fast. In addition, elevated circulating fatty acids after the fat meal could be used as fuel for muscle and other peripheral cells. The low and constant RER after the fat meal, indicating that mainly fatty acids were oxidised, is in line with this assumption. Thus, the fatty acid supply probably had a sparing effect on liver glycogen allowing a constant glucose supply to the brain. In addition, increased plasma levels of ketone bodies, which are used as brain fuels even under normal conditions and appear to stabilise or even improve some cognitive functions (Pollitt et al. 1981), may have contributed to the good cognitive performance after fat ingestion. Furthermore, EE was lowest and remained approximately at baseline after fat ingestion. Thus, less energy was spent for meal-induced thermogenesis. This situation was also reflected by the subjective ratings for 'cold' that were highest after fat ingestion. The G:I, which may reflect the state of metabolic activation, also remained approximately constant after fat ingestion. Improved cognitive functioning as a consequence of an optimal state of metabolic activation or arousal was reported by others (Nielson \& Jensen, 1994; Cahill \& McGaugh, 1996; Fery et al. 1997), and an 'inverted U'-shaped relationship was discussed (Davis et al. 1996; Fery et al. 1997). Since an 'inverted U'shaped relationship for memory function was also reported for plasma adrenaline (Borrell et al. 1984; Gold \& Stone, 1988; Cahill \& McGaugh, 1996) and insulin concentration (Kopf \& Baratti, 1995; Cahill \& McGaugh, 1996), such a relationship may also exist for the G:I. Thus, the approximately constant G:I after fat ingestion may have contributed to the good performance.

Metabolic changes after carbohydrate and protein ingestion. In contrast to fat, carbohydrate ingestion disrupted the constant baseline metabolism and resulted in an anabolic state. This state was characterised by high plasma glucose and insulin, as well as low plasma glucagon and fatty acid concentrations resulting in a low G:I. Moreover, the increase in RER, which exceeded the value 1.0 , indicated that in addition to increased glucose oxidation, lipogenesis from carbohydrates might have been initiated. Thus, EE was higher after carbohydrate ingestion than after fat ingestion. The better accuracy in short-term memory after carbohydrate ingestion than after protein ingestion may be due to the specific memory enhancement of glucose via cholinergic mechanisms (Dolezal \& Tucek, 1982; Durkin et al. 1992; Kopf \& Baratti, 1995) or to the insulin-induced sedative-like effect of serotonin. In contrast, protein ingestion resulted in a more activated catabolic state with lower plasma glucose and insulin, and higher plasma glucagon and fatty acid concentrations, as well as a higher G:I. The lower RER suggests that fatty acids or amino acids were mainly oxidised, and because of the high thermic effect of protein,
EE was higher than that after fat ingestion. Thus, the relatively better efficiency after protein ingestion compared with carbohydrate ingestion may be explained by a higher state of metabolic activation resulting in higher arousal. The glucagon concentration might be a good indicator of the extent of this meal-induced arousal, because an increased plasma glucagon concentration is known to be a primary counter-regulatory factor within the metabolic defence against moderate hypoglycaemia (Santiago et al. 1980; Santeusanio et al. 1981). In addition, the increased amino acid supply, which was reflected in the elevated urea concentration, could provide precursors for catecholamine synthesis.

\section{Integrating metabolic indices and cognitive performance}

Considering the results of our study, a more stable postprandial metabolism might have been responsible for the better cognitive performance observed after mixed meals compared with meals particularly rich in a single macronutrient (Berry et al. 1991; Lloyd et al. 1994; Cunliffe et al. 1997; Paz \& Berry, 1997). A combined consideration of metabolic changes rather than an individual metabolic index presumably explains how macronutrient ingestion in our study affected cognitive functions. Results of the correlation and regression analyses suggest that the metabolic activation state together with the plasma glucose concentration and/or the intensity of the amino acid metabolism are helpful indicators for these integrated mechanisms. The time- but not meal-dependent changes in plasma cortisol concentration also seem to be related to some cognitive functions (Borrell et al. 1984). However, to draw general conclusions about the influence of macronutrient ingestion on cognitive functions, quantitative effects (i.e. dose-response relationships between macronutrient ingestion and changes in metabolic indices as well as cognitive functions) must also be investigated in addition to qualitative differences between macronutrients.

\section{Conclusions}

In summary, in healthy young men, pure macronutrient ingestion in the morning influenced specific cognitive functions with different efficiency and time delay. Best and non-specific overall performance after fat ingestion was concomitant with stable glucose metabolism as well as G:I. Carbohydrate and protein ingestion both resulted in lower cognitive performance, which was accompanied by some marked changes in glucose metabolism and the G:I, and led to a relatively better accuracy or efficiency of cognitive tasks. Within past years, the glycaemic and insulinaemic indices of food, i.e. indices measuring the acute effect of food ingestion on changes in blood glucose and insulin concentration respectively, have been widely studied with regard to physical performance. Like these indices, a G:I index reflecting the protein:carbohydrate value of food might be helpful to characterise specific effects of food on mood and cognitive performance. 


\section{Acknowledgements}

We thank Tanja Sethre, Micha Dambach and Myrtha Arnold for their technical assistance, William Moses for metabolite analyses and Professor Dr med U. Boutellier for medical supervision. We are also grateful to the research volunteers and a number of assistants of our institute for their experimental assistance during the study. The study was supported by the Swiss Foundation for Nutrition Research.

\section{References}

Bellisle F, Blundell JE, Dye L, Fantino M, Fern E, Fletcher RJ, Lambert J, Roberfoid M, Specter S, Westenhofer J \& Westerterp-Plantenga MS (1998) Functional food science and behaviour and psychological functions. British Journal of Nutrition 80, Suppl. 1, S173-S193.

Berry EM, Growdon JH, Wurtman JJ, Caballero B \& Wurtman RJ (1991) A balanced carbohydrate:protein diet in the management of Parkinson's disease. Neurology 41, 1295-1297.

Borrell J, de-Kloet ER \& Bohus B (1984) Corticosterone decreases the efficacy of adrenaline to affect passive avoidance retention of adrenalectomized rats. Life Sciences 34, 99-104.

Cahill L \& McGaugh JL (1996) Modulation of memory storage. Current Opinion in Neurobiology 6, 237-242.

Craig A (1986) Acute effects of meals on perceptual and cognitive efficiency. Nutrition Reviews 44, Suppl., 163-171.

Cunliffe A, Obeid OA \& Powell TJ (1997) Post-prandial changes in measures of fatigue: effect of a mixed or a pure carbohydrate or pure fat meal. European Journal of Clinical Nutrition 51, 831-838.

Davis EA, Soong SA, Byrne GC \& Jones TW (1996) Acute hyperglycaemia impairs cognitive function in children with IDDM. Journal of Pediatric Endocrinology and Metabolism 9, 455-461.

De-Feo P, Gallai V, Mazzotta G, Crispino G, Torlone E, Perriello G, Ventura MM, Santeusanio F, Brunetti P \& Bolli GB (1988) Modest decrements in plasma glucose concentration cause early impairment in cognitive function and later activation of glucose counterregulation in the absence of hypoglycemic symptoms in normal man. Journal of Clinical Investigation 82, 436-444.

Diamond P \& LeBlanc J (1988) A role for insulin in cephalic phase of postprandial thermogenesis in dogs. American Journal of Physiology 254, E625-E632.

Dolezal V \& Tucek S (1982) Effects of choline and glucose on atropine-induced alterations of acetylcholine synthesis and content in the caudate nuclei of rats. Brain Research $\mathbf{2 4 0}$, 285-293.

Durkin TP, Messier C, de-Boer P \& Westerink BH (1992) Raised glucose levels enhance scopolamine-induced acetylcholine overflow from the hippocampus: an in vivo microdialysis study in the rat. Behavioural Brain Research 49, 181-188.

Fernstrom JD (1977) Effects on the diet on brain neurotransmitters. Metabolism 26, 207-223.

Fernstrom JD \& Wurtman RJ (1972) Elevation of plasma tryptophan by insulin in rat. Metabolism 21, 337-342.

Fery YA, Ferry A, Vom HA \& Rieu M (1997) Effect of physical exhaustion on cognitive functioning. Perceptual and Motor Skills 84, 291-298.

Gold PE (1995) Role of glucose in regulating the brain and cognition. American Journal of Clinical Nutrition 61, 987S995S.

Gold PE \& Stone WS (1988) Neuroendocrine effects on memory in aged rodents and humans. Neurobiology of Aging 9, 709717.

Holmes CS (1987) Metabolic control and auditory information processing at altered glucose levels in insulin-dependent diabetes. Brain and Cognition 6, 161-174.

Holt SH, Miller JC, Petocz P \& Farmakalidis E (1995) A satiety index of common foods. European Journal of Clinical Nutrition 49, 675-690.

Huber C (1994) Profile of Mood States, version 1.00. Mödling. Austria: Dr G. Schuhfried GmbH.

Kanarek R (1997) Psychological effects of snacks and altered meal frequency. British Journal of Nutrition 77, Suppl. 1, S105-S118.

Keul J, Huber G, Lehmann M, Berg A \& Jakob EF (1982) Einfluss von Dextrose auf Fahrleistung, Konzentrationsfähigkeit, Kreislauf und Stoffwechsel im Kraftfahrzeug-Simulator (Doppelblindstudie im cross-over-design) (Influence of dextrose on driving performance, ability to concentrate, circulation and metabolism in the automobile simulator (Double-blind study in crossover design)). Aktuelle Ernährungsmedizin in Klinik und Praxis 7, 7-14.

Kopf SR \& Baratti CM (1995) The impairment of retention induced by insulin in mice may be mediated by a reduction in central cholinergic activity. Neurobiology of Learning and Memory 63, 220-228.

Läubli T, Meile U, Rosselli E, Scheller M, Sethre T \& Krueger H (1998) Kombinationstest für psychotoxikologische Untersuchungen (Combi-test for psychotoxicological examinations). Schweizerische Medizinische Wochenschrift 128, 10S.

Lieberman HR, Corkin S, Spring BJ, Wurtman RJ \& Growdon JH (1985) The effects of dietary neurotransmitter precursors on human behavior. American Journal of Clinical Nutrition 42, 366-370.

Lieberman HR, Spring BJ \& Garfield GS (1986) The behavioral effects of food constituents: strategies used in studies of amino acids, protein, carbohydrate and caffeine. Nutrition Reviews $\mathbf{4 4}$, Suppl., 61-70.

Lloyd HM, Green MW \& Rogers PJ (1994) Mood and cognitive performance effects of isocaloric lunches differing in fat and carbohydrate content. Physiology and Behavior 56, 51-57.

McNair DM, Lorr M \& Droppleman LF (1971) Profile of Mood States Manual. San Diego, CA: Educational and Industrial Testing Service.

Mackay C, Cox T, Burrows G \& Lazzerini T (1978) An inventory for the measurement of self-reported stress and arousal. British Journal of Social Clinical Psychology 17, 283-284.

Nielson KA \& Jensen RA (1994) Beta-adrenergic receptor antagonist antihypertensive medications impair arousal-induced modulation of working memory in elderly humans. Behavioral and Neural Biology 62, 190-200.

Owen OE, Morgan AP, Kemp HG, Sullivan JM, Herrera MG \& Cahill GF Jr (1967) Brain metabolism during fasting. Journal of Clinical Investigation 46, 1589-1595.

Owens DS \& Benton D (1994) The impact of raising blood glucose on reaction times. Neuropsychobiology 30, 106-113.

Parsons MW \& Gold PE (1992) Glucose enhancement of memory in elderly humans: an inverted-U dose-response curve. Neurobiology of Aging 13, 401-404.

Paz A \& Berry EM (1997) Effect of meal composition on alertness and performance of hospital night-shift workers. Do mood and performance have different determinants? Annals of Nutrition and Metabolism 41, 291-298.

Pollitt E, Leibel RL \& Greenfield D (1981) Brief fasting, stress, and cognition in children. American Journal of Clinical Nutrition 34, 1526-1533.

Porrini M, Santangelo A, Crovetti R, Riso P, Testolin G \& 
Blundell JE (1997) Weight, protein, fat, and timing of preloads affect food intake. Physiology and Behavior 62, 563-570.

Rogers PJ (1995) Food, mood and appetite. Nutrition Research Reviews 8, 243-269.

Santeusanio F, Bolli G, Massi BM, De-Feo P, Angeletti G, Compagnucci P, Calabrese G \& Brunetti P (1981) Counterregulatory hormones during moderate, insulin-induced, blood glucose decrements in man. Journal of Clinical Endocrinology and Metabolism 52, 477-482.

Santiago JV, Clarke WL, Shah SD \& Cryer PE (1980) Epinephrine, norepinephrine, glucagon, and growth hormone release in association with physiological decrements in the plasma glucose concentration in normal and diabetic man. Journal of Clinical Endocrinology and Metabolism 51, 877-883.

Santucci AC, Schroeder H \& Riccio DC (1990) Homeostatic disruption and memory: effect of insulin administration in rats. Behavioral and Neural Biology 53, 321-333.

Sayegh R, Schiff I, Wurtman J, Spiers P, McDermott J \& Wurtman R (1995) The effect of a carbohydrate-rich beverage on mood, appetite, and cognitive function in women with premenstrual syndrome. Obstetrics and Gynecology 86, 520-528.

Schlich P (1993) Uses of change-over designs and repeated measurements in sensory and consumer studies. Food Quality and Preference 4, 223-235.
Smith A, Kendrick A, Maben A \& Salmon J (1994) Effects of fat content, weight, and acceptability of the meal on postlunch changes in mood, performance, and cardiovascular function. Physiology and Behavior 55, 417-422.

Smith A, Leekam S, Ralph A \& McNeill G (1988) The influence of meal composition on post-lunch changes in performance efficiency and mood. Appetite 10, 195-203.

Spring B, Maller O, Wurtman J, Digman L \& Cozolino L (1982) Effects of protein and carbohydrate meals on mood and performance: interactions with sex and age. Journal of Psychiatric Research 17, 155-167.

Stevens AB, McKane WR, Bell PM, Bell P, King DJ \& Hayes JR (1989) Psychomotor performance and counterregulatory responses during mild hypoglycemia in healthy volunteers. Diabetes Care 12, 12-17.

Weir JBdV (1949) New methods for calculating metabolic rate with special reference to protein metabolism. Journal of Physiology 109, 1-9.

Wurtman JJ, Brzezinski A, Wurtman RJ \& Laferrere B (1989) Effect of nutrient intake on premenstrual depression. American Journal of Obstetrics and Gynecology 161, 1228-1234.

Wurtman RJ \& Fernstrom JD (1975) Control of brain monoamine synthesis by diet and plasma amino acids. American Journal of Clinical Nutrition 28, 638-647. 